\title{
Reformismo y proscripción durante el gobierno de Julio Rivera El Salvador 1962-1964
}

Gerardo Monterrosa Cubías

Si una mayor polarización y una más fuerte represión ha sido el resultado de un descontento mayor con la actual distribución de la riqueza en Guatemala y El Salvador, uno se pregunta si la política de las clases dominantes en El Salvador puede seguir teniendo éxito por mucho más tiempo. Porque aún con el grado actual de libertad de organización política y proselitismo, el nivel de descontento y su reflejo en el apoyo a los partidos reformistas está destinado a crecer, de modo que será necesario suprimir los privilegios en grado significativo tal vez como se ha hecho en Perú o quizás permitiendo gobernar a un partido reformista o enfrentar una situación de polarización, tensión y esporádicos derramamientos de sangre como sucede en Guatemala. ${ }^{1}$

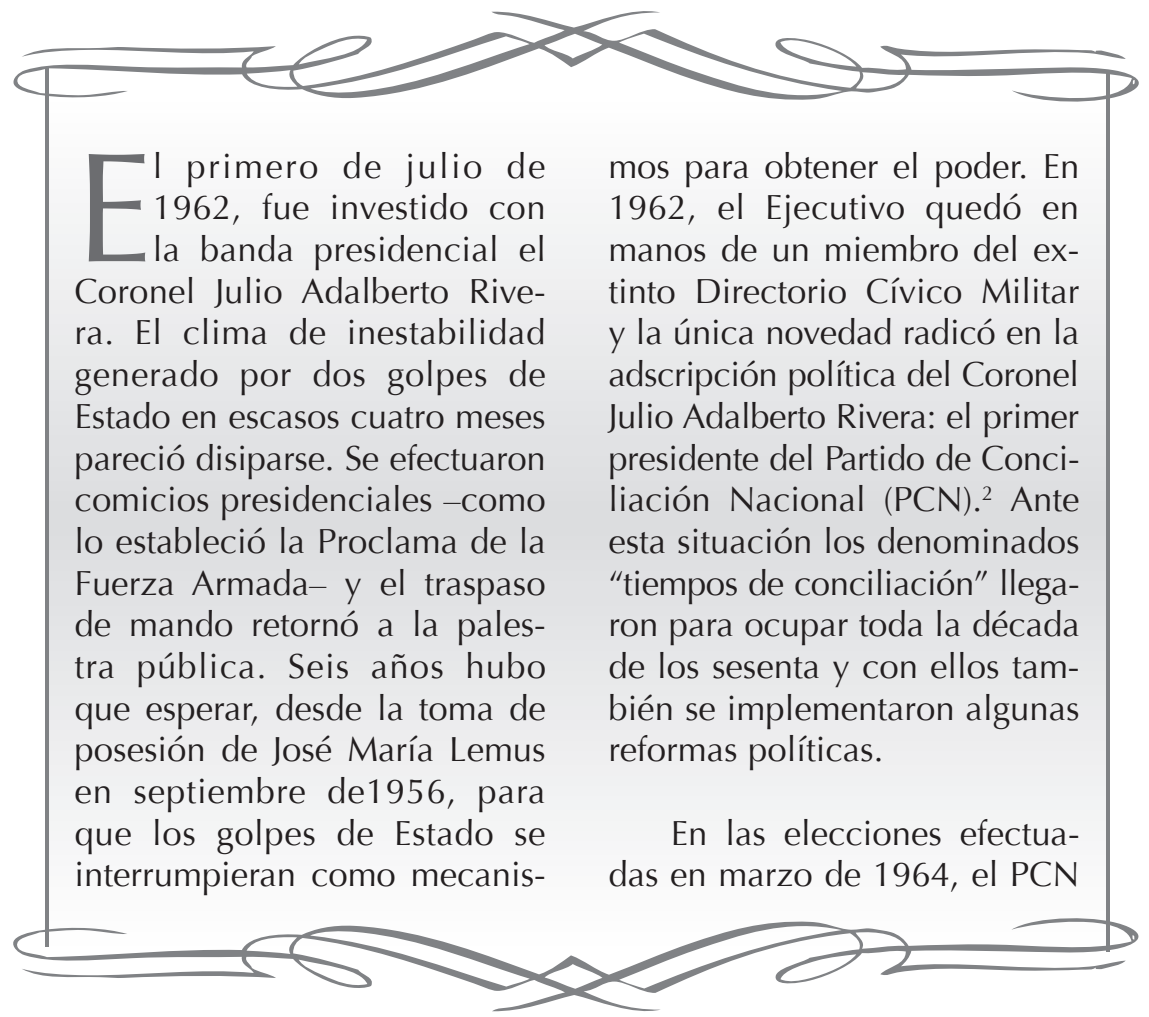


mantuvo la mayoría parlamentaria, pero ya no estaría solo, la oposición ocupó dieciocho escaños de los cincuenta y dos disponibles en la Asamblea Legislativa. El unipartidismo y las campañas de exclusión política hacia la oposición legalizada habían cedido ante la nueva estrategia del régimen militar que consistió, usando la expresión de Sara Gordon, en "incluir para excluir". ${ }^{3}$

Luego de esta breve contextualización -clave para indicar nuestro punto de partida temporal- es oportuno establecer el objetivo del presente artículo, el cual consiste en exponer los factores que incidieron en la implementación de la representación proporcional durante el gobierno de Julio Rivera
(1962-1967). ¿En qué ambiente político fue propuesta e incorporada al Código Electoral salvadoreño la representación proporcional? ¿Cuáles fueron los condicionamientos internacionales (Alianza para Progreso, Carta de Punta del Este) y nacionales (el clima de inestabilidad política que Rivera buscaba eliminar) que propiciaron la consumación de la representación proporcional en 1963? Asimismo ¿qué recepción tuvo en los partidos legalizados y proscritos por el régimen dicha reforma? Finalmente, ¿cuál fue la composición parlamentaria suscitada tras las primeras elecciones bajo la representación proporcional efectuadas en marzo de 1964? A responder estas interrogantes dedicaremos las siguientes páginas.



\section{Una reforma electoral para calmar los ánimos de la oposición}

En julio de 1962 el clima político salvadoreño distaba mucho de experimentar un momento de concordia. La oposición estaba inconforme con el procedimiento electoral que había permitido al coronel Julio Adalberto Rivera obtener la primera magistratura. A continuación, esbozaremos un recuento de las acciones gubernamentales que generaron el descontento de los partidos de oposición.

Primero, transcurridos dos meses luego de publicada la Proclama de la Fuerza Armada, el Directorio Cívico Militar, a través del Consejo
Central de Elecciones, convocó a los partidos legalmente inscritos -entre ellos al recién fundado Partido Demócrata Cristiano (PDC)- a organizar un Consejo Consultivo Preelectoral. El objetivo era elaborar reformas al código electoral que permitieran unas elecciones libres, con reglas claras y consensuadas. Sin embargo, el documento final -que incluía dichas recomendaciones- fue ignorado por el Directorio. Como lo expone Julio Adolfo Rey Prendes, fundador de la Democracia Cristiana, "el 30 de julio el Consejo Consultivo Preelectoral le entregó al Directorio un proyecto 
de Ley Electoral con la exigencia de que se aprobara lo antes posible y se convocara a elecciones para elegir a las autoridades que habían sido depuestas. Ante el prolongado silencio del Directorio, el
PDC retiró del Consejo Consultivo Preelectoral a sus delegados". ${ }^{4} \mathrm{Y}$ en este sentido, para justificar esta decisión afirmaron y prometieron lo siguiente:

El Partido Demócrata Cristiano reitera al pueblo salvadoreño su decisión de seguir luchando, hasta el sacrificio, con la fe inquebrantable de que sus esfuerzos en nombre de Dios y de la Patria, fructificarán pronto, sin necesidad de acciones subversivas, sino a través del esfuerzo cívico organizado, en la vigencia de una verdadera democracia. ${ }^{5}$

Luego de este desplante, vino otra acción que tomó por sorpresa a los partidos opositores, mismos que esperaban una convocatoria para elegir a las autoridades depuestas por el golpe de Estado perpetrado en enero de 1961. No obstante, el Directorio Cívico Militar anunció la celebración de elecciones para nombrar una Asamblea Constituyente que se encargaría de redactar la nueva Carta Magna. El 15 de diciembre de 1961 se efectuaron dichos comicios. Para participar en la contienda la oposición se agrupó en la Unión de Partidos Democráticos (UPD) conformada por la Democracia Cristiana -en su primera experiencia electoral-, el Partido de Acción Renovadora (PAR) y el Partido Social Demócrata (PSD). En estas elecciones participaron el PCN y la coalición. La UPD esperaba ganar algunos curules en la Constituyente, sin embargo, su pretensión se vio frustrada ante el triunfo arrollador del PCN. En los catorce departa- mentos obtuvo mayoría de votos y, gracias a la representación geográfica, ${ }^{6}$ la Asamblea Constituyente adquirió una composición habitual en aquellos años: unipartidista.

La oposición legalizada -como en otras ocasiones- quedó fuera de las instancias políticas definitorias. Las elecciones bajo la representación geográfica se convirtieron en el medio idóneo para legitimar la composición unívoca de la Asamblea Constituyente. El martes 2 de enero de 1962, los diputados pecenistas comenzaron a redactar la Constitución. El trabajo fue sumamente breve y el 8 de enero el Diario Oficial contenía en sus páginas la nueva Carta Magna. Las variaciones con respecto a la Constitución de 1950 fueron mínimas, sin embargo, el artículo 65 -específicamente en el cuarto inciso- se convirtió en la manzana de la discordia. La redacción se estructuró de la siguiente forma: 
El ciudadano que haya desempeñado la Presidencia de la República a cualquier título de los mencionados en este Artículo no podrá ser Presidente, Vicepresidente o Designado en el período presidencial inmediato. ${ }^{7}$

La frase "a cualquier título de los mencionados" posibilitó a Julio Rivera competir por la presidencia. ${ }^{8}$ El coronel -basándose en la modificación constitucional- era un miembro más del Directorio, no el presidente de la República en funciones. Por lo tanto, su inscripción fue aceptada por el Concejo Central de Elecciones. Con los obstáculos allanados el coronel Rivera, bajo el Partido de Conciliación Nacional, buscaría probar el apoyo popular que poseía su recién formado instituto político. Las elecciones se programaron para el 29 de abril de 1962, sin embargo, aún faltaba la última palabra de la oposición para decidir si se trataría de una contienda entre varios o de un monólogo partidista. Finalmente, éstos decidieron no presentar candidatos para la elección presidencial. La razón de dicha abstención se basó en dos promesas incumplidas por el Directorio: a) la fundación del PCN, que defenestró el compromiso de no organizar partidos políticos que respondieran a los intereses de los golpistas, y b) la candidatura de Rivera, misma que irrespetó el acuerdo de no lanzar para este cargo a ningún miembro del Directorio Cívico Militar. No obstante, la iniciativa de la oposición no representó ningún dato novedoso en el inestable escenario político salvadoreño; ya durante la campaña presidencial de 1956, los opositores habían dejado en solitario al candidato del PRUD: Teniente Coronel José María Lemus. Por ende, éste no tuvo rivales en las urnas y los votantes asistieron únicamente a ratificar su mandato. Iniciada la década de los sesenta $-y$ tras la promesa hecha por el Directorio de elecciones libres- el viento no parecía dirigirse en otra dirección.

Las críticas de diversos sectores sociales no se hicieron esperar y la Asociación General de Estudiantes Universitarios (AGEUS), organizó una protesta en contra del régimen de turno: acusaron de cobardes a los partidos de oposición por haberse retirado de la contienda y en respuesta lanzaron al ruedo político el Partido Estudiantil Salvadoreño (PES). El candidato presidencial sería presentado dentro de pocos días en la Plaza Libertad y para completar la fórmula solicitaron al Dr. Francisco Lima ${ }^{9}$-que ya era candidato a la vicepresidencia por el $\mathrm{PCN}$ - que acompañara bajo la misma postulación a su partido universitario. Francisco Lima declinó la propuesta por el compromiso previamente adquirido, pero agradeció a los estudiantes su invitación. Una actitud anuente tomó también el Dr. Francisco José Guerrero, ${ }^{10}$ pre- 
sidente de la Asamblea Legislativa, quien prometió a los estudiantes realizar todos los esfuerzos posibles por legalizar dicha organización política. Empero, todo se trataba de una sátira muy bien planificada. El día señalado para presentar al contrincante de Rivera, partieron los estudiantes en manifestación desde la Facultad de Medicina y en un camión llevaban al "candidato" que era un enorme burro vestido de militar. Víctor Valle, testigo de este acontecimiento, relata lo siguiente:

El desfile comenzaba con una manta que decía "Este burro es coronel y el coronel es burro". En todo el desfile había un mensaje subyacente que era el de denunciar la mascarada de la elección. También me recuerdo perfectamente que el último cartel del desfile era uno que decía: "Salvadoreño: por el bien de tu patria no votes". Era la forma que ACEUS tenía para darle a conocer al pueblo que no estaba a favor de esas elecciones y para persuadirle que no legitimara el triunfo de Rivera. ${ }^{11}$

No obstante, esta denuncia de los estudiantes universitarios y el retiro de los partidos de oposición, no representaron obstáculos para que las elecciones se llevaran a cabo el domingo 29 de abril de 1962. Julio Rivera resultó vencedor en solitario y asumió el cargo dos meses des- pués. Entre sus puntos de agenda se encontraba incorporar nuevamente a una oposición legalizada que había sido totalmente adversa y crítica de sus mecanismos para obtener el poder. En el discurso de toma de posesión el coronel Rivera lanzó un llamado a los partidos políticos:

Lo único que solicitamos a quienes no compartieron nuestras ideas en la pasada confrontación electoral, es que sepan juzgar correctamente nuestro propósito de conciliación nacional; que acepten como única definición legítima el dictado de la soberana voluntad popular, y que, como contingente cívicos evolucionados y cultos, no nieguen su concurso de inteligencia, patriotismo y honradez a las altas responsabilidades que el pueblo salvadoreño, deseoso de paz y de progreso, nos señala a todos por igual, sin discriminaciones ni reservas, como ciudadanos capaces de entender que El Salvador está por encima de cualquier interés personal deleznable. ${ }^{12}$

Estas palabras del presidente, buscaban enrumbar un proceso electoral que -como ya observamos- había dado muestras de fla- 
queza desde su puesta en marcha en marzo de 1961. Retomando el discurso inaugural de su quinquenio encontramos el anunció de una medida política que -según la perspectiva de Rivera- coadyuvaría a enaltecer los intereses de la nación:

A los partidos políticos corresponde, en este sentido, la obligación patriótica ineludible de reconocer que su verdadera misión está en ag/utinarse, no en torno a los individuos, sino a los principios, e inspirarse, no en los apetitos de un grupo, una clase social o una fuerza privilegiada, sino en los reclamos del interés supremo de la Nación. Consecuente con el espíritu de estas ideas, una de las mayores preocupaciones de nuestro gobierno será el estudio de una ley adecuada y práctica que confiera al Cuerpo Electoral el derecho de la representación proporcional en el órgano legislativo. ${ }^{13}$

$Y$ en efecto, el 11 de enero de 1963 Julio Rivera envió a través del Secretario General de la Presidencia, Carlos Armando Domínguez, una excitativa al Concejo Central de Elecciones (CCE) -presidido por el Dr. Rafael González Serrano- para elaborar un ante-proyecto que sustituyera la representación geográfica. El objetivo de esta reforma no era otro que instaurar la representación proporcional ${ }^{14}$. Así, la solicitud de los partidos de oposición -hecha con anterioridad- encontraba concreción. Empero, resulta clave señalar que el ya citado Consejo Consultivo Pre-electoral propuso la representación proporcional en el documento final que entregaron en 1961. Sin embargo, esta solicitud no había sido aprobada para las elecciones a la Constituyente, sino hasta 1963, es decir, cuando Julio Rivera cumplía su segundo año en la silla presidencial. En síntesis, las quejas del PDC ante la negligencia del Directorio alcanzaron eco con la entrada en vigencia de la representación proporcional. No obstante, la voluntad política de los involucrados hizo posible que Rivera se llevara los créditos. En plena consonancia con la promesa presidencial, el Consejo Central de Elecciones respondió el 8 de mayo de 1963 a la excitativa de Julio Rivera:

En atención a su nota de fecha 11 de enero del presente año a efecto de que se elaborara un ante-proyecto de reforma a la Ley Electoral, este Consejo, cumpliendo un deber patriótico, interpretando el sentir de la ciudadanía salvadoreña, y su promesa hecha al pueblo salvadoreños en su Mensaje Presidencial del primero de julio del año pasado, en cuanto a reformar la Ley Electoral, para hacer efectiva 
la representación o elección proporcional, ha elaborado un ante-proyecto de reformas de varios artículos de la ley electoral, y especialmente el Art. 139, de la mencionada Ley, que adjunto enviamos. Este proyecto ha sido enviado ya a la Asamblea Legislativa por medio del Ministro del Interior, por carecer este Consejo, de iniciativa de ley. ${ }^{15}$

"La nueva era con Rivera" -según el eslogan de la campaña electoral- había iniciado. El Consejo Central de elecciones -por medio del Ministro del Interior, coronel Fidel Sánchez Hernández- ${ }^{16}$ presentó el anteproyecto de Ley Electoral a la Asamblea Legislativa el 8 de mayo de 1963. La Representación Proporcional se introdujo en el artículo 139 que reza de la siguiente forma:

La elección de Diputados se determinará conforme al sistema de elección proporcional, de esta manera: se hará el recuento de votos válidos por cada Departamento, se divide este por el número de Diputados Propietarios que corresponde al Departamento, obteniéndose así el cociente electoral. Determinado dicho cociente los Partidos tendrán tantos Diputados como veces esté contenido el cociente electoral en el número de sufragios que haya obtenido en el Departamento respectivo. Si faltare un Diputado lo ganará el partido con mayor residuo; si faltaren dos, el segundo lo ganará el que siga en mayor residuo y así sucesivamente, hasta completar el número de Diputados por Departamento. ${ }^{17}$

A los tres meses de haber presentado dicha solicitud, la Asamblea Legislativa aprobó la reforma electoral. Las justificaciones giraron en torno a la experiencia, ya que los diputados aducían -en su informe final firmado por unanimidad-que mediante la representación geográfi- ca, fuertes sectores del cuerpo electoral no podían expresar sus puntos de vista en el pleno legislativo. Y en efecto, el unipartidismo en el Salón Azul fue una cuestión habitual en la década de los cincuenta. Por ende, los diputados estimaban que...

(...) la misma experiencia también ha demostrado que los partidos políticos, al frustrarse sus aspiraciones cívicas, pierden el impulso dinámico que debe caracterizarlos, para ser verdaderamente representativos de las ideas políticas predominantes en la nación. Que además es conveniente, para los altos intereses de la patria, que las Asambleas, 
correspondan, numéricamente, a la fuerza de los partidos políticos, para una efectiva intervención de todo el cuerpo electoral en la gestión de la actividad legislativa. Por lo tanto, la forma adecuada para que las representaciones de la mayoría y la minoría guarden proporción con la fuerza de la una y la otra, es el sistema electoral denominado proporcional y racional. ${ }^{18}$

Los diputados -por iniciativa del presidente Rivera- encontraron un sistema que apuntaba a expresar "racionalidad" en el sistema político. Las oportunidades de alcanzar un puesto en la Asamblea Legislativa se ensancharon para los partidos de oposición legalizados. En síntesis, la estrategia del régimen militar consistió en incorporar a la oposición al entramado parlamentario y esta acción acarreó enormes réditos para su estabilidad en el poder: los diputados opositores se convirtieron en funcionarios públicos y desde 1964 cualquier disenso debía resolverse en la tribuna legislativa, no en las calles y plazas públicas como había sucedido en las jorna- das de protesta contra el presidente José María Lemus en septiembre de 1960. En este sentido, mientras la oposición legal fue cobijada por un manto de apertura, las organizaciones de izquierda corrieron con una suerte distinta. Julio Rivera prosiguió el sendero de exclusión del Directorio y en 1963 ilegalizó nuevamente al Partido Revolucionario Abril y Mayo (PRAM), brazo electoral del Partido Comunista Salvadoreño (PCS). Por consiguiente, y para comprender mejor esta estrategia bifronte, debemos examinar el ambiente internacional, donde el clima de Guerra Fría iniciaba a tomar fuerza por iniciativa del gobierno estadunidense.

\section{La Alianza para el Progreso: una respuesta a la revolución latinoamericana}

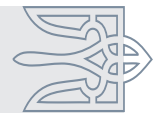

El 13 de marzo de 1961, se efectuó en la Casa Blanca una reunión entre John F. Kennedy -que llevaba menos de dos meses al mando del ejecutivo-, el cuerpo diplomático latinoamericano radicado en Washington y miembros del Congreso de los Estados Unidos. El anuncio de un viraje significativo en la política exterior estadunidense hacia América Latina fue el motivo fundamental de aquel encuentro. Un minucioso estudio sobre la situación del Hemisferio -conteniendo sus perspectivas de desarroIlo- había llegado a las manos del presidente Kennedy; asimismo, los acontecimientos reportados desde La Habana apresuraron la puesta en marcha de esta nueva etapa de las relaciones internacionales. ${ }^{19}$ Aquel día ante los diplomáticos 
latinoamericanos, Kennedy citó en su discurso nombres como los de Jefferson, Bolívar y San Martín. Estos personajes, representaban la fuente de inspiración de una nueva ola libertadora que se avecinaba para América Latina. Las cadenas a romper no provenían más de la sujeción colonial, sino de la pobreza imperante en esta parcela del continente. El presidente Kennedy, reconociendo la difícil situación latinoamericana, incluyó en su alocución un mea culpa e indicó los principales óbices que el nuevo programa debía superar:

Como ciudadano de los Estados Unidos de América, permítanme que sea el primero en reconocer que nosotros no hemos comprendido siempre el sentido de esta misión común, así como también es cierto que hay mucha gente en los países que representan ustedes que no han entendido por completo la urgente necesidad de librar al pueblo de la pobreza, la ignorancia y la desesperación. Pero procede ahora que superemos los errores, las fallas y las incomprensiones del pasado, en la marcha hacia un futuro lleno de peligros, pero resplandeciente de esperanza. ${ }^{20}$

La Alianza para el Progreso (ALPRO) representaba una forma totalmente novedosa de enfrentar los problemas latinoamericanos. Este proyecto -como bien lo apuntan Levinson y Onís- "no habría de ser simplemente un programa norteamericano de ayuda, sino un esfuerzo conjunto en el que todas las naciones americanas movilizarían sus recursos, enlistarían las energías de sus pueblos, y modificarían sus formas sociales de manera que todos y no tan sólo unos privilegiados, participaran de los frutos del progreso" ${ }^{\prime 21}$ Para concretar este monumental propósito, Kennedy estableció diez puntos en su discurso. A continuación citamos tres que se vinculan directamente con nuestra temática: a) una junta del Consejo Inter-Americano Económico y Social (la futura reunión de Punta del Este) para principiar el esfuerzo de planificación masiva que será la cabeza de la Alianza para el Progreso, b) una década de máximo esfuerzo y, muy relacionado con este aspecto, c) la contribución inicial de 500 millones de dólares proporcionados por los Estados Unidos que el presidente Kennedy estaba listo para pedir al Congreso.

El objetivo de este nuevo plan interamericano era alcanzar un desarrollo sostenido en la región y los especialistas afirmaron que en diez años la calidad de vida de todos los latinoamericanos no distaría mucho a la de los países industrializados. Por consiguiente, el crecimiento económico debía poseer fuertes repercusiones sociales y brindar a 
los sectores marginados aquellos servicios básicos que por tanto tiempo habían permanecido lejos de su alcance: techo, trabajo, tierra, salud y escuelas.

El anuncio realizado por el presidente Kennedy entusiasmó a muchos políticos latinoamericanos que en más de una ocasión habían solicitado al gobierno estadunidense -luego de observar el impacto positivo del Plan Marshall en una Europa devastada por la Segunda Guerra Mundial- un programa que incluyera una fuerte dosis de ayuda económica. Entre las personalidades centroamericanas que recibieron con beneplácito los puntos programáticos de la ALPRO estuvo el ex presidente costarricense José Figueres. En un estudio titulado "La Alianza para el Progreso: objetivos políticos" apuntó:

Nosotros consideramos esta alianza como una medida realista, como un medio defensivo del Gobierno de Estados Unidos. Eso es precisamente lo que esperábamos. Desde el tiempo de Bolivar sabemos que el bienestar de las Américas es indivisible. Nos sentimos satisfechos si Estados Unidos entra a esta pelea protegiendo sus propias libertades, o favoreciendo sus propios intereses, como quien hace una inversión reproductiva y no simplemente un gasto. Sabemos que el buen sembrador no lanza sus semillas a los pájaros silvestres. ${ }^{22}$

Las palabras de Figueres, ubican a la ALPRO en un entorno de confrontación continental y esto era precisamente lo que acontecía ante el viraje que había tomado la Revolución cubana. En los primeros meses de 1961, las relaciones entre La Habana y Washington experimentaron su último estertor. La Revolución cubana fue declarada socialista el 16 de abril de 1961 y la relación creciente con Moscú generó un clima de tensión entre Cuba y su ofendido vecino del norte. Ante este escenario, el gobierno estadunidense decidió erradicar las condiciones sociales, económicas y políticas que pudiesen representar un caldo de cultivo para que otro proceso revolucionario de izquierda estallara en el Hemisferio. En procura de este objetivo, la voluntad política de los gobiernos latinoamericanos y el apoyo monetario de Estados Unidos resultaba una amalgama fundamental. Como lo indica Friedrich Katz:

El triunfo de Fidel Castro en Cuba, también condujo a profundas transformaciones en la política norteamericana hacia América Latina. La política del "palo duro" practicada hasta 1959, fue reemplazada por una nueva política de "pan y palo". En la Alianza para el Progreso formulada por 
Kennedy, los Estados Unidos tuvieron por primera vez un programa de ayuda económica a América Latina. Al mismo tiempo en el discurso oficial norteamericano, la democracia jugó un papel mayor que en las épocas anteriores. ${ }^{23}$

El balneario de Punta del Este en Uruguay fue escenario de la reunión extraordinaria del Consejo Interamericano Económico y Social a nivel Ministerial. Las sesiones iniciaron el 5 de agosto de 1961 con el propósito fundamental de elaborar un documento con las líneas programáticas de la Alianza para el Progreso. La estructuración de dicho manuscrito respondió a una exigen- cia del gobierno estadunidense en el sentido que la implementación de ciertas reformas en los países latinoamericanos debía anteceder el otorgamiento de la anhelada ayuda económica. En la Carta de Punta del Este, luego de la "Declaración a los Pueblos de América", se estableció un apartado donde los países signatarios se comprometían durante los próximos años a...

\section{(...) perfeccionar y fortalecer las instituciones democráticas en aplicación del principio de autodeterminación de los pueblos. Acelerar el desarrollo económico y social, a fin de conseguir un aumento sustancial y sostenido del ingreso por habitante, para acercar en el menor tiempo posible, el nivel de vida de los países latinoamericanos al de los países industrializados. ${ }^{24}$}

A estos dos objetivos, se agregaron otros de capital importancia, a saber, la realización de reformas agrarias, fiscales y sociales. Además, la educación, erradicación del analfabetismo y la construcción de viviendas populares engrosaron una lista de requisitos que los gobiernos latinoamericanos debían cumplir. En síntesis, la ALPRO buscaba instaurar un desarrollo económico que repercutiera en el bienestar de la población menos favorecida y, para lograr este objetivo, -en palabras de Kennedy - "la libertad política debe acompañar al progreso material. Nuestra Alianza para el Progreso es una alianza de gobiernos libres y debe esforzarse por eliminar la tiranía de un hemisferio en que no tiene derecho a estar". ${ }^{25}$

En la reunión de Punta del Este, luego de estipular los compromisos de los signatarios, se estableció el mecanismo de coordinación de la ALPRO, el cual postulaba tres planos para su ejecución: el nacional, interamericano e internacional. En el segundo se incluyó un grupo de Nueve Expertos que revisarían los planes de desarrollo presentados por cada nación latinoamericana; el plazo otorgado fue de 18 meses $y$, 
como lo indica Elena Ortega Aranda, "Ios Estados Unidos declararon que la ayuda sería, no a los países más necesitados, sino a los que den pruebas de estar dispuestos a introducir mejoras institucionales y reformas esenciales que se traduzcan en el mejoramiento de vida de sus clases populares". ${ }^{26}$ Es importante subrayar que los personeros de este programa reconocían las diferencias existentes entre las naciones latinoamericanas, no obstante, cada gobierno tendría que demostrar su aplicación tesonera en el trabajo encomendado. Raúl Sáez, miembro del Comité de Nueve Expertos de la ALPRO, explicó este aspecto:

Es esta idea de maximizar el esfuerzo interno lo que lleva simultáneamente a la de realizar determinadas reformas según las condiciones propias de cada país: reforma agraria, reforma tributaria, reforma administrativa, reforma educacional, reforma de la legislación del trabajo y social. Nadie fija un patrón para estas reformas. Cada una de ellas depende de las características del propio país. (...) pero es indispensable que para que el país tenga derecho a recibir y a esperar una ayuda exterior importante pueda demostrar que su esfuerzo interno realmente es el máximo que se puede hacer sin sacrificar las condiciones de vida o, más bien dicho, mejorando las condiciones de vida de sus clases populares. ${ }^{27}$

El "sendero del desarrollo" se había establecido para América Latina y solamente un representante en dicha conferencia decidió abstenerse de plasmar su rúbrica en la Carta de Punta del Este: Ernesto Guevara Cerna, quien encabezaba la delegación cubana. Paulatinamente el interés de los medios de comunicación y los asistentes se centró en la posición de Guevara y una posible confrontación con Douglas Dillon, republicano que Kennedy nombró Secretario del Tesoro. No obstante, pese a los discursos opuestos que cada uno pronunció -Guevara adjetivando la Alianza para el Progreso como "instrumento del imperialismo económico" y Dillon acusándolo de "falsear gravemente la posición de Estados Unidos"_-28 el altercado no pasó a más. Sin embargo, la disputa entre ambos personeros probó lo irreconciliables que eran sus posturas antípodas en el terreno político.

En 1962, cuando fue celebrado el primer aniversario de la ALPRO, el presidente Kennedy expresó una frase que ratificaba la importancia de las reformas en Latinoamérica: "Aquellos que hacen imposible una revolución pacífica harán una revolución violenta inevitable" ${ }^{\prime 29} \mathrm{En}$ dicho mensaje, el mandatario esta- 
dunidense hizo hincapié en los inconvenientes que enfrentaba la nueva política en algunos sectores del Hemisferio. Verbigracia, el atraso de muchos gobiernos en la entrega de sus programas de desarrollo. Sin embargo, el discurso de Kennedy aún evidenciaba su confianza en el cambio de rumbo planificado:

Durante mucho tiempo mi país, la nación más rica de un continente pobre, dejó de asumir plenamente sus responsabilidades con respecto a las hermanas repúblicas. De la misma manera, aquellos que poseen riquezas y poder en naciones pobres deben aceptar sus propias responsabilidades. Deben ponerse al frente de la lucha por estas reformas básicas, que son las únicas que pueden preservar la estructura de sus propias sociedades. ${ }^{30}$

Al mismo tiempo que las perspectivas de la ALPRO eran evaluadas en Washington por las autoridades responsables; Julio Adalberto Rivera arribaba a su segundo mes al mando del ejecutivo. La promesa de reformas políticas -concernientes al terreno electoral- se había anunciado, el Mercado Común Centroamericano estaba en funcionamiento y los poderes del Estado preparaban la implementación formal de la representación proporcional. A continuación, examinaremos las discusiones que suscitó la ALPRO en tierras salvadoreñas y los discursos reformistas que algunos personeros del gobierno sostenían. En este sentido, las palabras de John F. Kennedy, plagadas de optimismo, nos introducen en el tema:

Ya se libran campañas electorales sobre las cuestiones de la Alianza para el Progreso. Ya los gobiernos se están comprometiendo a cumplir con las disposiciones de la Carta de Punta del Este. Ya los pueblos a través del Hemisferio, en escuelas, sindicatos obreros, cámaras de comercio, establecimientos militares, gobiernos y granjas, han aceptado los objetivos de la carta como compromisos personales y políticos propios. ${ }^{31}$

\section{La Alianza para el Progreso en la mesa de debate}

El 15 de agosto de 1963, se llevó a cabo la cuarta Jornada de la Alianza para el Progreso en El Salvador. ${ }^{32}$ Esta reunión -organi- zada por la Oficina de la Unión Panamericana- tuvo como tema central la relación entre "El sector privado y la Alianza para el Progre- 
so". Los invitados que discutieron el tema provenían de diversos sectores: sindicales, gubernamentales, partidos de oposición legalizados, académicos, estudiantes universitarios y empresarios que asistieron en representación de la Cámara de Comercio e Industria $(\mathrm{CCl})$ y la Asociación Salvadoreña de Industriales (ASI). La exposición que inauguró esta sesión de trabajo estuvo a cargo del Dr. Ulises Flores, representante en El Salvador del Banco Centroamericano de Integración Económica (BCIE), quien, señalando la problemática suscitada entre la empresa privada y el Directorio Cívico Militar en 1961, defendió la planificación económica estatal como uno de los mandatos de la Alianza para el Progreso ${ }^{33}$. Al respecto afirmó:

En realidad éste es un elemento que causa alguna desconfianza en la iniciativa privada. Se dice que la planificación es una injerencia indebida en la iniciativa privada. (...) yo creo que la planificación de las actividades del Estado es completa y absolutamente necesaria. Ahora es bueno preguntar, ¿hasta dónde la injerencia de la planificación va a invadir campos de la iniciativa privada? Pero esta es una cosa de grado y medida, esto es una cosa de discutirla constantemente; cada vez que la planificación quiera tener injerencia en la iniciativa privada en una forma peligrosa debemos de saltar todos para evitar que esto suceda. Pero no debemos de desconfiar de la planificación económica. ${ }^{34}$

Dos años antes de esta cuarta Jornada, exactamente en los últimos meses de 1961, el ambiente político salvadoreño pasaba por una etapa de inestabilidad y controversia. Las pugnas al interior del Directorio Cívico Militar -concernientes al rumbo político que el gobierno debía tomar- provocaron no sólo la renuncia de muchos funcionarios del gabinete, sino también serias divergencias con la empresa privada. El principal reclamo de este sector se basó en el papel periférico que el Directorio les otorgó ante el proyecto suscrito en Punta del Este.
Además, aducían que el gobierno de turno había invadido espacios que competían únicamente a la iniciativa privada. Roberto Palomo Sol, presidente de la Asociación Salvadoreña de Industriales y presente en la cuarta Jornada de la ALPRO, realizó un llamado para evitar las vicisitudes afrontadas: "Señores, yo únicamente quisiera agregar que los industriales estamos convencidos de que si logramos llegar a una firme colaboración del sector público y del sector privado, podremos encontrar fácilmente el mejor método de resolver nuestros problemas" ${ }^{35}$ 
En agosto de 1963, el punto álgido de la confrontación entre el Ejecutivo y la iniciativa privada había pasado. El coronel Julio Rivera - que llevaba menos de dos años al mando de Casa Presidencial- daba muestras de poseer una postura más anuente hacia las demandas empresariales. Así lo indican las apreciaciones de Ulises Flores, quien afirmaba en esta reunión: "ahora que en el gobierno de El Salvador parece que la pesadilla ha pasado, que se ha aprendido la lección que el gobierno no puede actuar con la iniciativa privada como si fuera un elefante, (...) parece que hay una conciencia de que no podemos depender sólo de créditos extranjeros -sobre todo- ahora que se presenta la oportunidad del Mercado Común Centroamericano".$^{36}$

Sin embargo, la problemática salvadoreña no se agotaba en las buenas intenciones de ambas partes por establecer relaciones armónicas y fructíferas. Por el contrario, los problemas que acarreaba la caída de los precios del café en el mercado internacional y la inestabilidad política, representaban serias amenazas en la consecución del objetivo trazado en esta coyuntura: erradicar la marginación socioeconómica que grandes capas poblacionales enfrentaban. En este sentido, José Napoleón Duarte, representante de la Democracia Cristiana en la discusión pública, tomó la palabra y cuestionó la presencia de muchos sectores que lucieron ausentes en Jornadas anteriores de la ALPRO. Además, aprovechó la ocasión para interpelar a los empresarios y lanzar un mensaje a la élite económica salvadoreña. Elaborando una respuesta a la masiva concurrencia, en un tono bastante crítico, afirmó:

La razón, posiblemente, sea porque aquí se comienzan a tocar intereses propios; la razón, posiblemente, es porque los problemas de salud, de educación, de esa serie de problemas fundamentales de la nación no son tan interesantes como plasmar cuál es la posición de desarrollo económico del país y en qué posición estaría yo, con mi empresa y mis negocios, y qué ventajas o qué compromisos, o qué dificultades voy a tener en el problema de eso que se nos viene encima de la planificación económica. Se ha dicho mucho de que no estamos preparados para la democracia; pero señores cuando los elementos de la élite de este país no se quieren o no pretenden ocuparse de todos los problemas integrales que tenemos, si la educación es menos importante que la iniciativa privada, cómo vamos a salir, cómo vamos a hacer de este país, un país de bienestar, (...) un país de felicidad para todos los salvadoreños. ${ }^{37}$ 
Luego de la alocución de Napoleón Duarte, tomó la palabra Tomás Guerra, en representación de AGEUS, quien continuó el debate con la siguiente exhortación: "Yo invito y sé que en esto hay mucha osadía, a que nos pongamos todos a aportar nuestro esfuerzo para encontrar la manera adecuada de cambiar la estructura económica que ha retrasado el desarrollo de nuestro pueblo". ${ }^{38}$ Estas dos intervenciones, provenientes de sectores críticos de la urdimbre política y económica imperante en el país, ilustran la suspicacia existente hacia los sectores empresariales, pues según Guerra y Duarte, éstos no estaban realizando los esfuerzos necesarios para cumplir las metas que en la Carta de Punta del Este se habían establecido. Empero, estos señalamientos no quedarían sin respuesta ante los presentes en esta sesión de trabajo. Los representantes de la iniciativa privada encontraron en la figura del Doctor Antonio Rodríguez Porth, ${ }^{39}$ delegado de la Cámara de Comercio e Industria, su defensor en aquella ocasión. Éste abrió su discurso criticando las doctrinas ideológicas -mencionando directamente la obra de Karl Marx- que pretendían ser las "depositarias de la sensibilidad social". Además, cuestionó las acusaciones formuladas por Duarte hacia los cuadros empresariales presentes ese día, pues...

(...) es así como el sector de la iniciativa privada se ha visto tachado de falto de sensibilidad social, y por consiguiente, objeto de ataques enconados. Quiero afirmar que también este sector de la iniciativa tiene sensibilidad social. En otras palabras, el sector de la iniciativa privada le interesa ver la miseria erradicada, comparte la idea de una mejor justicia social. También desea que los niveles de vida sean elevados. ${ }^{40}$

No obstante, esta anuencia hacia las reformas fue introducida en su discurso con una aclaración: Rodríguez Porth estableció la diferencia entre una justicia social plagada de fines meramente político-propagandísticos y aquella que contenía una "sana economía", misma que permitía -según su perspectiva- mejorar las condiciones de vida de la población y dotar de sustento material dicho concepto. Retomando la definición de "sana economía", interpeló la prelación estipulada en la Carta de Punta del Este, pues en este documento, como lo examinamos, las reformas fiscales debían implementarse al mismo tiempo que las de tipo político, social y educativo. Para este ideólogo de la derecha salvadoreña, por el contrario, las reformas políticas y educativas debían anteceder cualquier tipo de reforma fiscal, pues en países como El Salvador, con una "economía subdesarrollada", cualquier golpe al ámbito económico ponía en riesgo las demás reformas 
programadas. Sin embargo, pese a las objeciones con respecto al orden de ejecución de la reforma fiscal, Rodríguez Porth coincidió con la pretensión fundamental de esta iniciativa panamericana y al respecto apuntaba:

Todos reconocemos los propósitos buenos de la Alianza para el Progreso. Se pretende mejorar las condiciones de vida de los países hispanoamericanos y a través de esta elevación de las condiciones de vida, se pretende preservar el sistema democrático de gobierno en nuestro Hemisferio. Los principios, los objetivos son elevados, son sanos y creo que todos estamos en condiciones de compartirlos. ${ }^{41}$

En síntesis, los participantes no cuestionaban los grandes objetivos propugnados por la ALPRO, sino las líneas programáticas que dicho programa debía seguir en El Salvador. Es decir, la pretensión era lograr un consenso en cuanto a los proyectos urgentes y viables para erradicar los graves problemas económicos, políticos y sociales. Como lo indicamos en páginas anteriores, los gobiernos estaban comprometidos a elaborar un plan de reformas que el grupo de Nueve Expertos debía examinar para realizar recomendaciones $y$ hacer efectivo el desembolso económico. En este sentido, la discusión que hemos plasmado -grosso modo- responde precisamente a esa búsqueda de acuerdos que generaran un clima de estabilidad al momento de ejecutar las reformas. El Doctor Jorge Castellanos Sol, ${ }^{42}$ en su condición de particular en esta discusión, sugirió una distinción fundamental entre el concepto de la ALPRO y su ejecución. En su disertación afirmó:

La Alianza para el Progreso como concepto, fundamentalmente está en la Carta de Punta del Este, que nadie se atreve a disputar que los objetivos y los medios generales de acción que ahí propone se apartan de lo que es la aspiración de la inmensa mayoría de latinoamericanos. El resto es una cuestión enteramente nacional desde el punto de vista del gobierno que adopta cual o tal programa desde el punto de vista de la opinión pública, que se pronuncia en tal o cual forma o cual aspecto de la Alianza. ${ }^{43}$

La diferenciación realizada por Castellanos Sol instaura dos planos: a) el conceptual, que estableció como principal meta el mejoramiento de las condiciones de vida de la población -techo, trabajo, salud y educación- a través de diversas reformas y $b$ ) el 
ámbito nacional, donde la agenda programática del gobierno debía vincularse con los grandes objetivos planteados por la Carta de Punta del Este. En síntesis, la discusión suscitada en la cuarta Jornada de la ALPRO nos permite indicar, a modo de conclusión en este apartado, el común acuerdo de los participantes en impulsar las reformas necesarias para viabilizar el postulado esencial de la ALPRO: "preservar las instituciones democráticas mediante el mejoramiento de las condiciones económicas, políticas y sociales". En este sentido, ¿cómo delineó este objetivo la agenda programática del gobierno presidido por Julio Rivera? La respuesta a esta pregunta constituye nuestro siguiente paso. Empero, antes de iniciar, es necesario realizar una aclaración: nuestro propósito no consiste en estipular el grado de cumplimiento de las promesas presidenciales realizadas en este quinquenio, sino dilucidar la influencia de la ALPRO en los proyectos gubernamentales, específicamente en las alocuciones del presidente y el ministro del Interior. Indicado nuestro objetivo, entremos en materia.

\section{Los objetivos del discurso reformista}

El primero de julio de 1965, el coronel Julio Rivera pronunció en la sede de la Asamblea Legislativa el informe sobre su tercer año de gestión al mando del Ejecutivo. ${ }^{44}$ Luego de indicar los objetivos alcanzados, entre ellos la implementación de la representación proporcional, realizó una exhortación que evidenciaba el objetivo fundamental de su quinquenio:

Invito a todos los salvadoreños a luchar contra el comunismo mejorando la educación, los salarios y la salud; no permitiendo la infiltración roja en los partidos políticos, desoyendo las voces disociadoras e impidiendo el acceso de extremistas a la dirigencia de los sindicatos obreros. ${ }^{45}$

Estas palabras del presidente salvadoreño, permiten constatar un elemento que señalamos anteriormente, a saber, el talante bifronte de la estrategia gubernamental emprendida desde 1962. Las reformas en el ámbito político, social y económico eran acompañadas por el cierre de los espacios hacia las ideologías "contrarias a la democracia". Esta lucha contra la "amenaza roja" al- bergaba un proyecto cuyo propósito era menguar $-\mathrm{o}$ en el mejor de los casos erradicar- las condiciones de exclusión y marginalidad que pudiesen provocar un descontento politizado. La revolución cubana, como bien lo indica Guilles Bataillon, había hecho que "el mito de la frugalidad de esas mayorías pobres se quebrantara, y comienza a aceptarse la idea de que el riesgo 
de caos social resulta más bien de la renuncia de las elites agroexportadoras a satisfacer algunas reivindicaciones populares, porque privar así de esperanza a los desheredados es empujarlos a prestar oído a la "demagogia comunista" ${ }^{46}$ Enmarcado en este propósito, Fidel Sánchez Hernández, ejerciendo sus funciones de ministro del Interior, dio la bienvenida en enero de 1964 a los participantes de la Segunda Reunión de Ministros de Goberna- ción de Centroamérica y Panamá. La Sede de la Organización de Estados Centro Americanos (ODECA) en San Salvador sirvió de escenario para dicho evento, que contó con la asistencia de Nichols Karembech, subsecretario de Justicia de los Estados Unidos. En el discurso de inauguración, Sánchez Hernández enfatizó el derrotero que resultaba imperioso instaurar para evitar el avance del comunismo en el istmo centroamericano:

Estamos aquí reunidos nuevamente para continuar nuestra labor de coordinación y programación conjunta, a fin de contribuir a garantizar la seguridad y libertad de los pueblos del istmo, frente a la subversión del comunismo internacional. Está probado, que el comunismo, no puede prosperar en los países donde existe una democracia vigorosa. Cuando hayamos logrado establecer la vigencia plena de democracias fuertes en nuestro medio, es probable que logremos nuestro afianzamiento político. ${ }^{47}$

La presencia de una numerosa delegación estadunidense en esta reunión evidencia el acompañamiento que las autoridades de este país otorgaban a los asuntos de defensa regional. La "amenaza comunista" -según los informes de los ministros de gobernación del área- se cernía sobre Centroamérica y afirmaban que "la subversión continúa llegando en forma de adiestramiento, propaganda, armas y fondos". ${ }^{48}$ Ante esta situación imperante en 1964, y tras un recorte presupuestario que el Congreso estadunidense realizó a la ALPRO, el senador por el estado de Nueva York, Robert Kennedy, hermano del presidente asesinado en noviembre de 1963, hizo un Ilamado al Senado para continuar impulsando los objetivos planteados en Punta del Este. Lyndon Johnson presidía ahora el ejecutivo $y$, pese a los cambios abruptos acaecidos en la política estadunidense, la situación latinoamericana continuaba requiriendo -según la perspectiva de Robert Kennedy- el apoyo anunciado en marzo de 1961:

El status quo en América Latina no puede conservarse, pero la cuestión medular que se nos plantea no es si podemos 
impedir el cambio, sino -como lo expresó el presidente Kennedy- si las "aspiraciones insatisfechas del hombre por el progreso económico y la justicia social pueden lograrse mejor al contar con hombres libres que trabajen dentro de un marco de instituciones democráticas". ${ }^{49}$

Las impresiones de Robert Kennedy, asesinado cuatro años después de esta alocución cuando competía por las primarias presidenciales del partido demócrata, eran resultado de un viaje que realizó por el hemisferio, donde constató según sus palabras, que "los pueblos de la América Latina tienen el mismo espíritu, las mismas esperanzas, la misma fe e iguales deseos para el futuro que el pueblo de los Estados Unidos. Hay que reconocer ese hecho -afirmaba el entonces senador- al desarrollar cualquiera de estos programas y normas, si queremos hacer bien las cosas". ${ }^{50}$ ¿Por qué incluir en este punto -destinado a la dinámica interna- el discurso de Robert Kennedy? El propósito es el siguiente: establecer la vinculación existente en 1964 -a tres años de implementada la ALPRO- entre el "espíritu de reformas" vigente en algunos personeros del gobierno estadunidense y los mensajes que Sánchez Hernández y Julio Rivera expresaban. Un claro ejemplo de lo anterior aparece en el informe del tercer año de gestión presidencial, donde Rivera afirmaba:

No habrá tranquilidad ni crecimiento económico, si continúan subsistiendo clases marginales a las cuales no llegan los beneficios del alza de precios de nuestros productos básicos en el mercado externo, ni los recursos derivados del progreso industrial, agrícola y comercial del país. ${ }^{51}$

El mensaje de Rivera reconocía la existencia de serios problemas en la distribución de la riqueza generada por las distintas actividades productivas del país. En este sentido, resulta oportuno formular la siguiente interrogante: iqué escenario enfrentaban los programas que el primer gobierno "pecenista" debía implementar para cumplir los objetivos establecidos en la Carta de Punta del Este? La respuesta implicaría un estudio socio-económico, sin embargo, alejados de esta inten- ción, la contestaremos indicando brevemente las coordenadas objetivas, es decir, los indicadores de carácter económico y socio-demográficos a los cuales se enfrentaban los propósitos gubernamentales.

Iniciamos este sucinto recorrido señalando el crecimiento poblacional originado en El Salvador en un período de catorce años. En la nación más pequeña en territorio de América continental, con aproximadamente 21,000 Kilómetros cua- 
drados, la población incrementó de 1,8 millones de habitantes en 1950 a 2.5 en 1964. ${ }^{52}$ Este crecimiento se distribuyó de la siguiente forma: $60 \%$ en el área rural y el $40 \%$ en zonas urbanas..$^{53}$ Sin duda alguna, esta distribución poblacional hacía que los descensos internacionales en el precio de los productos de exportación y las pésimas condiciones laborales prevalecientes en el campo, se convirtieran en los fundamentos materiales de una vida precaria que miles de familias salvadoreñas enfrentaban cotidianamente. Una revisión del ingreso por habitante y su distribución sustentan el juicio anterior. En efecto, desde 1950 hasta 1970 el ingreso per cápita incrementó en El Salvador. El impacto favorable del Mercado Común Centroamericano provocó que éste pasara de 489 dólares estadunidenses en 1950 a 720 registrados para el año de $1970^{54}$. Sin embargo, la distribución de este ingreso continuó por los senderos de la inequidad, pues desde 1960 hasta 1970, el 20\% de la población más pobre recibió únicamente el 5.5\% y el $20 \%$ más rico el $60 \%$ de este ingreso. Esta concentración de los ingresos en una quinta parte de la población propiciaba la existencia de una situación social excluyente: el grado de analfabetismo en 1960 alcanzaba el $51 \%$ y la matrícula inicial en educación primaria, media y superior rondaba los $339 \mathrm{mil}$ alumnos en este mismo año. ${ }^{55}$

La precaria condición socioeconómica de las "mayorías populares", usando la expresión de Ignacio Ellacuría, ${ }^{56}$ en un país que debía experimentar un crecimiento económico -según los planes de la ALPRO- era el reto que los gobiernos de turno debían ejecutar. Por consiguiente, el quinquenio presidencial inaugurado en 1962 era el responsable de iniciar con esta monumental empresa luego de la inestabilidad política suscitada en 1961. En cumplimiento de este compromiso, el coronel Julio Rivera -en el discurso pronunciado ante la nueva Asamblea Legislativa en 1964- no desaprovechó la oportunidad para indicar los trabajos que se realizaban en procura de este objetivo:

La gestión gubernativa tiene por objeto el bienestar de los salvadoreños a través del fortalecimiento de la economía nacional. Estamos ejecutando programas intensivos de saneamiento, alcantarillados, dotación de agua potable, energía eléctrica y construcción de escuelas. Estamos trabajando activamente en una nueva red nacional de carreteras y en un sistema moderno de telecomunicaciones. Los programas masivos de construcción de viviendas para las clases económicamente débiles. (...) la fundación de la Financiera Nacional de la Vivienda; la construcción de Hospitales y 
Centros de Salud, evidencian la preocupación del Gobierno por extender los beneficios de la gestión pública a las clases sociales que más necesitan del apoyo gubernamental. ${ }^{57}$

Las obras antes mencionadas, formaban parte de una estrategia que perseguía -a través de las reformas- la conformación de un frente unido contra el comunismo. "La lucha más importante -indicaba Julio Rivera en el informe del tercer año de gobierno- debe ser librada en el campo de las relaciones económico-sociales, por medio del aumento en el nivel de vida de las clases laborantes".$^{58}$ Como podemos observar, la famosa frase del presidente John F. Kennedy, citada en páginas anteriores, donde afirmó en tono de advertencia: "Aquellos que hacen imposible una revolución pacífica harán una revolución violenta inevitable", resonaba en los discursos del coronel Rivera. En este sentido, Guilles Bataillon, analizando este período de la vida política centroamericana, denomina este nuevo papel que asumió el ejecutivo como un "estado de compromiso". Describiendo sus características Bataillon establece lo siguiente:

La respuesta a la amenaza subversiva no debe limitarse a las medidas coercitivas que permitan relegar a las mayorías a un estatus de ciudadanía bajo tutela y de eterna indigencia. Es necesario dar cabida por lo menos a una parte de sus demandas. Asimismo, se estima necesario darle cierto reconocimiento a los nuevos estamentos sociales -clases medias urbanas en pleno crecimiento- mediante la apertura del juego electoral. A partir de entonces -el Estado- comienza a perfilarse como el conciliador de los intereses de los diferentes sectores de la sociedad. (...) La conformación del orden social mediante la conciliación de una pluralidad de intereses requiere, pues, en forma imperativa la acción del Estado; y precisamente en virtud de esa función de conciliación éste se convierte en agente primordial de la modernización económica y social. ${ }^{59}$

Ante este paradigma del "Estado de compromiso" que los gobiernos del hemisferio se comprometieron a dinamizar, el talante reformista de un mandatario militar como Julio Rivera salta a un primer plano. Sin embargo, este elemento, evalua- do a largo plazo, muestra -desde nuestra perspectiva- la génesis del conflicto armado salvadoreño, pues fue ante el fracaso de estas reformas planteadas con carácter de urgencia cuando las protestas sociales no encontraron otra respuesta que la 
represión indiscriminada por parte del Estado. Empero, esta fase represiva, iniciada con mayor fuerza en la década de los setenta, tuvo su antesala en los años que nos ocupan, donde las medidas para contener el comunismo comenzaron a adquirir un talante regional. En la segunda Reunión de Ministros de Gobernación el coronel Julio Rivera, aludiendo a los desafíos que implicaba la defensa del istmo, señaló:

La acometida del comunismo internacional en nuestros países, está demostrada con hechos que han conculcado las libertades individuales y colectivas en algún país de nuestra América. Hemos observado sus incidencias negativas en la vida institucional de varios pueblos latinoamericanos y por eso es que nosotros, los habitantes istmeños, debemos preocuparnos porque nuestros pueblos no sean abatidos por esa confabulación de tipo internacional. ${ }^{60}$

El clima de Guerra Fría recorría la región. Y en El Salvador el sistema de apertura restrictiva constituyó la estrategia para incluir a la oposición tolerada en la dinámica parlamentaria y excluir del plano electoral a los partidos de izquierda. La instauración de este sistema de apertura restrictiva ha sido examinado - hasta el momento- a través de los siguientes puntos: a) el clima político desde el cual se instauró la representación proporcional, b) la influencia de la ALPRO en el "ambiente reformista" y c) la adopción de los postulados de la Carta de Punta del Este por el gobierno de Julio Rivera. Nuestro siguiente paso será analizar las primeras elecciones bajo la representación proporcional efectuadas en marzo de 1964. El abordaje de este último punto incluirá un breve estudio del ambiente preelectoral suscitado desde agosto de 1963 hasta marzo de 1964. Como siguiente paso, revisaremos la composición parlamentaria derivada de estos comicios, así como la forma en que fue evaluado este evento por diversos analistas políticos en la prensa salvadoreña.

\section{Entre el escepticismo y la crítica: el escenario político ante los primeros comicios bajo la representación proporcional}

El 5 de marzo de 1964, a sólo tres días de celebrarse comicios legislativos y municipales, representantes de los partidos políticos en contienda (PAR, PCN y PDC) fueron invitados por el coronel Ju- lio Rivera a Casa Presidencial. Los puntos a tratar en esta reunión eran los siguientes: a) reiterar el compromiso adquirido por el ejecutivo de garantizar elecciones libres y b) escuchar las apreciaciones que estos 
delegados partidistas poseían sobre el proceso electoral. La presencia de tres ministros del gabinete: Fidel Sánchez Hernández, ministro del Interior; Humberto Cuestas, ministro de Justicia y Aurelio Zapata, ministro de Defensa; confirmó el objetivo primordial de esta convocatoria: dotar de credibilidad los comicios venideros. Empero, ¿Qué factor convirtió este tipo de iniciativas en necesarias para obtener la confianza del cuerpo electoral? La respuesta se encuentra en las desavenencias que anteriores procesos electorales habían suscitado. La estrategia de los representantes del Partido Revolucionario de Unificación Democrática (PRUD) -que gobernó El Salvador desde 1950 hasta 1960- consistió en obstaculizar, con diversos argumentos legales, la participación de sus contrincantes políticos. El resultado habitual de las elecciones -fueran éstas presidenciales o municipales y legislativas- era el reclamo airado de la oposición y el silencio complaciente del Consejo Central de Elecciones. En este sentido, ¿había cambiado esta situación en 1963? El clima político previo a las elecciones se caracterizó -como lo hemos indicado en el título de este apartado- por el escepticismo de la oposición legalizada y la crítica de aquella proscrita por el régimen. Una larga sombra de elecciones fraudulentas alcanzaba a esta nueva contienda y los crasos errores del pasado eran recordados en el siguiente editorial:

El Poder Público, entre nosotros ha desnaturalizado el proceso de las elecciones en una inmensa mayoría de casos. Desde mucho antes de iniciarse una campaña electoral, la maquinaria del gobierno se ha puesto, invariablemente, en marcha de aceleración creciente, a fin de hostigar, amedrentar o anular todo esfuerzo de los partidos políticos de "oposición". Nada escasas han sido las denuncias contra diversas clases de abusos por parte de las autoridades. Y esto no es únicamente una verdad histórica, sino una amarga experiencia vivida por muchos ciudadanos. Esa experiencia hace que el ciudadano dude o vacile frente a las declaraciones gubernamentales, desde las que expresa un ministro hasta las que salen del propio presidente. (...) La realidad ha sido una cosa, las declaraciones otra. ${ }^{61}$

Además, el editorialista señalaba, tomando en cuenta el ambiente reformista que la Alianza para el Progreso promovía hacia el Hemisferio, las consecuencias que traería para el entramado político salvadoreño un experimento democrático fallido. Al respecto afirmaba: "Estamos viviendo una época en que los procedimientos antidemocráticos ya 
no pueden usarse sin causar daños irreparables, tanto en el prestigio internacional, como en el desarrollo interno de los países" ${ }^{62}$ En este sentido, aunando esfuerzos para evitar desenlaces negativos -en unos comicios que prometían erradicar el unipartidismo en la Asamblea Legislativa- la oposición (PAR y PDC) aceptaron dialogar con el presidente de la República y los ministros antes citados. La reunión se prolongó por cinco horas y en la conversación el representante Democratacristiano, Abraham Rodríguez ${ }^{63}$-secundado en sus intervenciones por José Napoleón Duarte- analizó el ambiente preelectoral:

(...) se refirió al paso dado para lograr la representación proporcional en la próxima Asamblea Legislativa. Manifestó al respecto que aunque esa era una aspiración nacional desde hace muchos años, había que reconocer al actual gobierno su decisión de llevarla a cabo. ${ }^{64}$

No obstante, este reconocimiento se hizo acompañar de un pliego de peticiones, insistiendo -específicamente- en el papel que debía jugar la Guardia Nacional el día de las elecciones. Los partidos de oposición solicitaban a los Cuerpos de Seguridad una declaración pública en la que manifestaran que estaban dispuestos a acatar su apoliticidad en los próximos comicios. Al explicar las razones de esta petición, Abraham Rodríguez afirmó "que los agentes de la Guardia Nacional ejercían gran presión entre el campesinado para que votaran por el partido oficial y que una declaración como la que solicitaban podía evitarlo. Para nuestro campesino analfabeto, carente de educación cívica, -indicó Rodríguez- manda más un agente de la Guardia Nacional que el propio presidente de la República". ${ }^{65}$ La respuesta del coronel Julio Rivera no se hizo esperar: "declaró que lo que se pedía ya lo habían hecho privadamente los jefes de la Fuerza Armada y que habían ofrecido respetar la libertad de elecciones. Pedirles una declaración pública -indicó el mandatario- sería desconfiar del Ministro de Defensa, y de los jefes de los cuerpos de seguridad pública, que han ofrecido su lealtad y eso para mí sería incómodo". ${ }^{66}$

La dinámica de esta reunión, efectuada en Casa Presidencial, muestra dos elementos que configuraron el clima preelectoral desde agosto de 1963 hasta marzo de 1964. Por un lado, los esfuerzos gubernamentales por concretar unos comicios transparentes $y$, por el otro, la negativa de la oposición legalizada a ingresar en una dinámica proselitista plagada de artimañas practicadas en el pasado. A continuación reconstruiremos este ambiente preelectoral mediante las declaraciones de diversos actores 
políticos; sus posturas permitirán entrever los problemas de la urdimbre proselitista en este período, así como las propuestas expresadas para conseguir la tan ansiada democratización de los procesos electorales. Iniciemos este breve recorrido estableciendo los reclamos de la oposición legalizada y las acciones gubernamentales por solventar sus demandas. En efecto, el 14 de septiembre de 1963 el PAR publicó un comunicado de prensa donde indicaba lo siguiente:

\section{(...) no basta la voluntad, sino que también es imprescin- dible que la lucha se desarrolle sin la intervención obstruc- cionista de quienes tienen en sus manos la responsabilidad orgánica del evento. (...) A estas alturas, el PAR advierte que ya no es posible engañar al pueblo y quienes lo preten- den, están jugando con fuego". ${ }^{67}$}

Este mensaje del PAR surgió ante algunas exigencias que el Consejo Central de Elecciones (CCE) solicitaba para inscribir candidatos a diputados y alcaldes. El punto en discordia era una constancia expedida por la Corte de Cuentas, misma que ratificaba la solvencia de todo aquél que hubiese manejado fondos públicos. La dirigencia del PAR consideraba que este documento -debido a problemas de diversa índole en su entregaimpediría la inscripción de muchos de sus candidatos. Ante este impase suscitado, el gobierno de la República no tardó en proponer una solución. La Asamblea Legislativa, mediante la iniciativa del presidente Julio Rivera, aprobó el decreto transitorio 493, mismo que permitió a los distintos candidatos inscribirse y posteriormente cumplir con este requisito. ${ }^{68}$ El final de esta controversia fue sellado con la participación del PAR en las elecciones del 8 de marzo de 1964. El eslogan de este instituto político: "Sufragio efectivo. No imposición" -nótese el parecido con el del Partido Revolucionario Institucional (PRI) de México- Cobraba vigencia ante la anuencia gubernamental.

Por otro lado, la Democracia Cristiana, que asistía a su segunda contienda electoral, también exigió ciertas condiciones para que su bandera apareciera en las papeletas de votación. El Dr. Lara Velado, en su condición de Secretario General del Partido, ${ }^{69}$ envió al presidente de la República una misiva donde le recordaba sus promesas realizadas: una total libertad debía caracterizar las próximas elecciones si Julio Rivera -según el democristiano- estaba dispuesto a cumplir su palabra. Bajo el lema "Por la justicia social dentro de un régimen de auténtica democracia", Lara Velado estipuló el reto que las autoridades competentes poseían ante las próximas elecciones: 
(...) es bueno recordar que nuestro pueblo está cansado del engaño político y de simples declaraciones líricas que no se cristalizan en realidades concretas. De aquí que su gobierno, si en verdad está dispuesto a cumplir con la ley y la moral permitiendo y propiciando un evento electoral libre, debe suprimir los hechos que han creado en el pueblo la desconfianza y el temor. ${ }^{70}$

Este clima preelectoral -con una oposición demandante y suspicazllevó al ministro del Interior, coronel Fidel Sánchez Hernández, a reiterar las garantías que el gobierno ofrecía para los comicios. En una nota periodística indicó: "Espero que los partidos legalmente constituidos respondan a esta manifestación de buena fe con el interés cívico capaz de lograr el perfeccionamiento de la vida política nacional. Invito, enfatizó, a los dirigentes políticos a tener fe y absoluta confianza en la firme promesa del gobierno de unas elecciones completamente libres". ${ }^{71}$ Este afán por convencer al cuerpo electoral de las genuinas intenciones gubernamentales hizo que el coronel Rivera sostuviese también una reunión con los Gobernadores departamentales. Un matutino publicó las palabras dirigidas por el mandatario. En su alocución no faltaron las apreciaciones sobre los vaivenes de la campaña electoral, sin embargo, hizo gala del optimismo que el Ejecutivo poseía ante los comicios venideros: "Venturosamente podemos decir que estamos trabajando con mucha fe en la época más difícil que se ha presentado en los últimos años". ${ }^{72} \mathrm{Su}$ carta de presentación -para atraer a los partidos políticos legalizados en esta "época difícil"- era la ley de representación proporcional que se pondría en marcha en las próximas elecciones. Este paso -según las palabras de Rivera- podría calificarse como trascendental,

\section{(...) porque significa un avance hacia la democratización en} nuestro medio. Esta Ley implica muchos esfuerzos para poderla realizar e incluso conlleva algunos riesgos en el orden político -apuntó-, pero ofrece a cambio grandes beneficios que traerá a nuestra vida democrática. Significa, además, un cambio fundamental, puesto que no había habido gobierno que se atreviera a dar oportunidad a las minorías a fin de que en el Cuerpo Legislativo estuvieran representadas, con riesgo de la mayoría. ${ }^{73}$

Asimismo, el Dr. Francisco José Guerrero, Secretario General del $\mathrm{PCN}$ y presidente en funciones de la Asamblea Legislativa, expresaba similares apreciaciones. En una entrevista concedida a un rotativo 
evaluó de manera positiva la puesta en marcha de la representación proporcional, aduciendo "que este paso dado por los representantes del Partido -refiriéndose al $\mathrm{PCN}-$ para fomentar el desarrollo democrático, debe ser apreciado por la ciudadanía consciente como un verdadero avance en el programa político del país". A continuación el entrevistador le preguntó por la desconfianza que algunos elementos representativos de los partidos de oposición habían externado sobre las elecciones de marzo próximo. El Dr. Guerrero indicó que este rasgo era normal en ese sector político, no obstante, los instó a participar para poner a prueba la nueva ley electoral. El Secretario General del PCN afirmó que...

(...) históricamente la oposición en todo momento ha expresado desconfianza. Es una posición tradicional. Sin embargo, para las próximas elecciones, cabría traer a la memoria las elecciones del 17 de diciembre de 1961. (...) si esa elección se hubiese regido por la reforma del artículo 139 de la Ley Electoral, que establece la representación proporcional, al seno de la Asamblea Nacional hubieran llegado por lo menos diecisiete diputados de la oposición, de acuerdo con los resultados de la elección citada. Esta consideración valdría la pena de ser tomada muy en cuenta por los Partidos de oposición al decidir su participación en el próximo evento electoral. ${ }^{74}$

Mientras las declaraciones del presidente de la Asamblea Legislativa alentaban a la oposición permitida por el régimen, ¿Qué sucedía con el Partido Revolucionario Abril y Mayo (PRAM) que tenía vedado el derecho a decidir su participación en estos comicios? Su actividad se desenvolvió en los márgenes de los medios de comunicación. No obstante, los volantes (hojas sueltas) se convirtieron en los canales para expresar su rechazo al gobierno de Rivera. Proscritos en diversas ocasiones por el Consejo Central de Elecciones, la última realizada en abril de 1963, esta organización era catalogada como "contraria a la democracia" por la ideología que sustentaba. El PRAM, fundado en 1960 con el objetivo de convertirse en el brazo electoral del Partido Comunista Salvadoreño (PCS), tomó su nombre de los meses de 1944 cuando el descontento de la población salvadoreña -que culminó en la "Huelga de Brazos Caídos" - logró derrocar al general Maximiliano Hernández Martínez, personaje al que denominaban los miembros del PRAM como teósofo masacrador de 30 mil campesinos. ${ }^{75}$ Este adjetivo en alusión al genocidio perpetrado durante su mandato en los primeros meses de 1932. Además, reivindicaban -bajo la consigna de "Lucha 
por la patria y la libertad"- a los caídos en las protestas acaecidas en septiembre y octubre de 1960 contra el coronel José María Lemus.

Esta actitud contestataria hacia el régimen militar -al que tildaban de tiranía- ${ }^{76}$ se incrementó ante las elecciones que se avecinaban en 1964. En un comunicado, la dirigencia del PRAM externó su inconformidad ante la proscripción que el Consejo Central de Elecciones les había decretado y, en este sentido, estimaban que de nada servían las reformas al Código Electoral si la exclusión política continuaba vigente. $\mathrm{Al}$ respecto afirmaban:

Los preparativos de las elecciones próximas se están desarrollando fundamentalmente en el marco de las condiciones impuestas por la tiranía: está vigente una Ley electoral que, pese a las reformas introducidas el año anterior, conserva todo su contenido fascista; con apoyo en esa ley, se ha impedido la libre organización y funcionamiento de partidos políticos, estando el PRAM precisamente en este caso; este mismo hecho imposibilita a los distintos sectores sociales y políticos participar con sus propias organizaciones y sus propios candidatos en las elecciones; se mantiene además un ambiente de temor en el país provocado por la permanente represión policiaca y las restricciones a la libertad de expresión; está intacto, en fin, el aparato tradicionalmente usado por la imposición oficial para frustrar la libre expresión de la voluntad popular. ${ }^{77}$

Ante este escenario, el PRAM exhortaba al pueblo salvadoreño a votar por los partidos de oposición, pues mediante esta acción el sufragio sería contra del "despotismo y el imperialismo". Además, indicaron que el pueblo debe votar por aquel Partido o por aquellas planillas o aquellos candidatos que mejor levanten las siguientes demandas populares:

Por la unidad de todas las fuerzas democráticas, por la libertad de organización de todos los trabajadores del campo, por la completa independencia del movimiento sindical, contra la represión por motivos políticos, por el respeto a las libertades públicas, por la reforma de la Ley electoral y la irrestricta libertad de organización política, por la derogación de la "Ley anticomunista, contra la penetración de los monopolios imperialistas y, finalmente, por la defensa de la soberanía popular. ${ }^{78}$

La postura del PRAM ante las elecciones municipales y legislativas de 1964 muestra la otra cara de la moneda, es decir, el descontento ante un régimen que, pese a la incorporación de la representación 
proporcional al Código Electoral, continuaba practicando el cierre de espacios hacia los partidos ubicados a la izquierda del espectro político. Sin embargo, el posicionamiento del PRAM evidencia un rasgo característico de este tipo de organizaciones durante la década de los sesenta, a saber, la credibilidad que aún poseían en los partidos políticos y en la vía electoral. En el caso que examinamos, el PAR y el PDC -según el comunicado del PRAM- eran los indicados para implementar las reivin- dicaciones políticas que la izquierda no podía concretar ante la exclusión impuesta por el Consejo Central de Elecciones. Por consiguiente, lejos de realizar un llamado a boicotear las elecciones, como fue habitual en la década de los ochenta, depositaban en los votantes la responsabilidad de elegir los programas políticos que respondieran a las demandas estipuladas por esta organización. La propaganda antigubernamental del PRAM concluía con la siguiente recomendación:

Pueblo Salvadoreño: Este es un momento de lucha, y no de descanso ni de transigencia con el despotismo. Pese al ambiente antidemocrático en que se desarrolla el proceso electoral, tu participación masiva en la votación debe hacer del 8 de marzo una jornada de repudio contra el actual régimen. Debemos todos vigilar las maniobras imposicionistas del gobierno y debemos luchar contra sus atropellos y arbitrariedades. ¡VOTAR CONTRA EL PARTIDO OFICIAL ES VOTAR CONTRA LA TIRANÍA Y EL IMPERIALISMO! !9

Estos señalamientos críticos, realizados en febrero de 1964, se sumaron a las manifestaciones de escepticismo que ya configuraban el ambiente preelectoral. La pregunta que permeaba la antesala de los comicios era la siguiente: ¿Podría la voluntad política del gobierno -mediante la colaboración de todas sus instancias ministeriales- concretar unas elecciones libres y dotadas de ecuanimidad? Un suceso -muy curioso- acaecido en febrero de 1964 parecía indicar que el gobierno realizaba acciones en procura de este objetivo. El coronel Marco Aurelio Zapata, ministro de Defensa, envió un comunicado de prensa donde manifestaba que "está empeñado en secundar los propósitos del Presidente de la República, en cuanto a garantizar un clima de absoluta libertad en las próximas elecciones. Por ello, (...) Carteles con el texto del artículo 114 de la Constitución Política, ${ }^{80}$ serán colocados en cuarteles y lugares públicos, para ratificar la apoliticidad del Ejército Nacional ante el próximo evento electoral" ${ }^{81}$ En medio de este ambiente llegó el día de los comicios. El escepticismo, la crítica y el optimismo de los actores políticos pasaban al plano factual, mismo 
que probaría el talante acertado o infundado de sus posturas. Las votaciones para elegir 261 alcaldes y 52 diputados se disputaron entre tres institutos políticos: PAR, PDC y el partido oficial PCN. A continuación, el examen de sus resultados y las opiniones que generó esta contienda electoral representa el objetivo de nuestro último apartado.

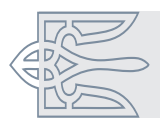

\section{Una nueva composición parlamentaria, ¿el comienzo de una era democrática?}

El domingo 8 de marzo de 1964, el electorado salvadoreño asistió a las urnas a votar por sus representantes a nivel legislativo y municipal. Por primera vez, la composición parlamentaria sería elegida a través de la ley de representación proporcional. Esta variante en el Código Electoral aseguraba a los partidos opositores su presencia en el Salón Azul del Palacio Nacional. Los comicios estaban sustentados por un registro electoral a nivel nacional de $1,027,831$ salvadoreños empadronados, según los datos del Consejo Central de Elecciones. ${ }^{82}$ El evento se desarroIló sin mayores inconvenientes, los cuerpos de seguridad cumplieron su mandato constitucional y la espera por los resultados comenzó en las sedes de los institutos políticos. Julio Adolfo Rey Prendes, candidato a la diputación por San Salvador en aquella ocasión, narra el júbilo con el que recibieron las primeras noticias llegadas al recinto del PDC:

Nuestro entusiasmo creció cuando entró Napoleón Duarte y nos dijo: "Hemos ganado San Salvador". "Pero hay que organizarnos para cuidar los votos porque han pedido recuento. Según nuestros datos, Duarte -candidato por la Alcaldía de la capital- había sacado 1,400 votos arriba de su contrincante del PCN. Siguieron llegando los datos de las diferentes alcaldías en donde habíamos obtenido triunfos. En total fueron 24 alcaldías ganadas. (...) El triunfo del PDC en el departamento de San Salvador era increíble, el pesimismo con que se habían elegido los candidatos desapareció por completo y muchos se lamentaron de no haber creído en el nuevo sistema de elección proporcional desde el principio, por lo que no aceptaron ser candidatos. ${ }^{83}$

El conteo de votos, en el caso de la Alcaldía capitalina, se efectuó nuevamente y en esta segunda ocasión el triunfo de José Napoleón
Duarte fue irrevocable. El PDC administraría la municipalidad más importante del país por dos años. De hecho, esta victoria no 
sería la única que festejarían los democristianos, pues muchos datos continuaron Ilegando y, a través del complejo mecanismo de elección proporcional, este partido ganó un total de catorce curules en la Asamblea Legislativa. En pocas palabras, el PDC se convirtió en la segunda fuerza política en su cuarto año de existencia. Sin duda alguna, el bastión electoral -en materia de elección legislativa- se encontraba en la capital salvadoreña. Los votos a su favor en este departamento sumaron 29,140 , siendo muy superiores a las papeletas marcadas por su bandera en San Miguel donde apenas alcanzaron 4,949. En claro contraste con esta proporción se ubicó el partido oficialista, mismo que en Usulután, Santa Ana y La Libertad obtuvo triunfos arrolladores sobre sus oponentes. El PCN se convirtió en el partido más votado de los comicios, adjudicándose como resultado la mayoría parlamentaria con un total de treinta y cuatro diputados. Mientras tanto, el menos favorecido en esta jornada fue el PAR, ya que el número de votos sólo le concedió cuatro curules en el Salón Azul.
La representación proporcional se había concretado. Los temores que caracterizaron los días previos a la elección se disiparon y, por supuesto, el coronel Julio Rivera recibió muchos elogios por su promesa cumplida. El eslogan "La nueva era con Rivera" cobraba vigencia y muchas notas periodísticas coincidieron en reconocer su decidido liderazgo en el exitoso proceso electoral. El impacto propagandístico de este evento hacia su gestión gubernamental fue muy importante; todos los esfuerzos realizados -reuniones con los representantes de los partidos en contienda, gobernadores y la coordinación con diversos ministros- habían rendido sus frutos. El coronel Rivera comenzaba a concretar reformas en materia política y orquestaba de esta forma su mandato con uno de los objetivos estipulados en la Carta de Punta del Este, mismo que exhortaban a sus signatarios a "perfeccionar y fortalecer las instituciones democráticas en aplicación del principio de autodeterminación de los pueblos. ${ }^{84}$ En este sentido, un anónimo, sin rayar en posturas aduladoras, afirmó lo siguiente en un rotativo salvadoreño:

No vamos a darle las gracias a nadie por este pequeño pero valioso respiro democrático, pues era una obligación de los gobernantes, a la par que un derecho del pueblo, el respetar y cumplir los principios en que se basa nuestra civilización. Sin embargo, merece el más entusiasta reconocimiento la integridad de los gobernantes -en especial el Presidente Rivera- por apegarse a la línea recta y atender a las exigencias del soberano. Y no andaríamos errados al decir que el mejor ganancioso después de la prueba ha sido precisamente el Gobierno. ${ }^{85}$ 
Sin embargo, no todos los elementos que constituyeron estos comicios adquirieron un talante favorable, verbigracia, el nivel de abstencionismo que rondó el $73 \%$ del registro electoral. ${ }^{86}$ Esta cifra, nada halagadora para aquellos que vieron en estas elecciones una oportunidad ingente para que el electorado participara masivamente, fue analizada en algunas notas periodísticas. Las apreciaciones sobre esta apatía adquirieron dos matices. Por un lado, aquellos que minimizaron este aspecto aduciendo que "las elecciones del domingo pasado mantienen aún el interés del pueblo. Y puede decirse de ellas, que si bien es cierto que no votó la totalidad de la ciudadanía, no existe en estos momentos un solo habitante del país que no esté interesado en conocer los resultados definitivos" ${ }^{\prime \prime}{ }^{87}$ Otra perspectiva de análisis, mucho menos optimista que la anterior, reconoció el gran esfuerzo realizado por las autoridades competentes en los comicios, no obstante, este marcado abstencionismo fue abordado desde otra ruta explicativa:

Si es cierto que no todos votaron el domingo, el motivo es harto conocido: en épocas anteriores el pueblo ha sido engañado con elecciones cuyo resultado se sabían antes de que la gente concurriera a las urnas. El pueblo ha sido burlado con elecciones amañadas, "técnicamente prefabricadas". Y por eso hubo apatía el domingo. Pues no se puede hacer cambiar de modo de pensar a un pueblo-de la noche a la mañana- cuando por muchísimos años se le ha engañado, con la imposición de candidatos postulados por el partido oficial. ${ }^{88}$

Una vez más, pese al repunte democristiano y los reconocimientos hacia el coronel Rivera, el pasado fraudulento -según la perspectiva de este analista- influía en la decisión del electorado. Por lo tanto, el reto del nuevo partido oficial consistía en erradicar las prácticas arbitrarias que su predecesor -el PRUD de Oscar Osorio- había ejercido en desmedro de la credibilidad electoral. La confianza en el mejoramiento progresivo de los comicios era evidente en esta coyuntura. Una novedosa etapa de democratización parecía instaurarse en El Salvador. Así lo indican las palabras de Tarquino Rosales, analista político, quien señaló al respecto:

No podía haberse intentado un mejor homenaje a la memoria del ex presidente Kennedy cuya proclamación de la Alianza para el Progreso cumplió 3 años el 13 de este mes y cuya iniciativa en tal sentido abrió horizontes de esperanza 
entre las muchedumbres latinoamericanas sobre la conquista del progreso político, económico y social. ${ }^{89}$

Empero, la concreción de esta "nueva etapa" dependía también de los avances en materia socioeconómica. Por otra parte, si la composición multipartidista de la Asamblea Legislativa se había concretado, también el cierre de los espacios políticos formaba parte de esta estrategia. El sistema de apertura restrictiva permitió a la oposición legalizada desde 1964 -sobre todo al PDC- aumentar su apoyo popular y peso definitorio en el entramado político. Sin embargo, mantuvo proscrita a la izquierda política de los procesos electorales. Si estos dos elementos se enmarcan dentro del rotundo fracaso de las reformas socio-económicas programadas, podemos iniciar a configurar las paradojas que marcaron el rompimiento de este equilibrio -acaecido en 1972 con el fraude electoral en contra de la Unión Nacional Opositora (UNO)- y los orígenes del conflicto armado desde la década de los sesenta. Sin duda alguna, un trabajo aún pendiente en la historiografía de nuestro país.

\section{A manera de epílogo}

Los comicios municipales y legislativos, celebrados en marzo de 1964, marcaron un hito en la vida electoral salvadoreña. Luego de muchas peticiones frustradas por parte de la oposición, el tan esperado sistema de representación proporcional -que aún se mantiene vigente- permitió que el Salón Azul perdiera su tinte unipartidista. La "nueva era con Rivera" alcanzaba concreción. Empero, más allá de la mera descripción de este acontecimiento, lo que hemos estudiado en el presente artículo son las causas tanto locales como internacionalesque permitieron su implementación. Definitivamente, esta reforma fue hija de su tiempo, de una década que se caracterizó en sus inicios por el impacto de la Revolución cubana, el debate suscitado en El Salvador ante este suceso, los planes del Gobierno estadunidense por frenar su influencia y los discursos que colocaron -como en el caso de Rivera- un mayor acento en mejorar las condiciones de vida de los salvadoreños para evitar una revolución violenta.

La denominada guerra fría comenzó a impactar de lleno el istmo centroamericano. $Y$ en medio de este ambiente, se instauró una estrategia bifronte para el caso salvadoreño. Por un lado, el primer gobierno del PCN permitió la incorporación de la oposición legalizada a la vida parlamentaria. Los democristianos -que mantuvieron su buena racha electoral a lo largo de 
la década- ganaron 14 curules en 1964. En este sentido, los diversos editoriales de la época reconocieron el avance democrático y todo parecía indicar que bajo el espíritu de la Alianza para el Progreso, el país se alejaba paulatinamente del tiempo de las asonadas y la inestabilidad. No obstante, a la par de este proceso, también se llevó a cabo un cierre de espacios políticos hacia los partidos considerados "ajenos a la democracia". El PRAM fue ilegalizado y las denuncias de éstos no se hicieron esperar. Pese a los reclamos, Julio Rivera aunó esfuerzos por evitar que la experiencia de la Junta Cívico Militar -acusada de comunista ante su reformismo y que sólo duró tres meses en el poder- se repitiera. A partir de 1962, el anticomunismo focalizó su proyecto en dos puntos cardinales: las reformas en materia política, social y económica y, por otro lado, la contención directa de esta ideología a través de iniciativas regionales como la CONDECA.

En síntesis, el estudio de estos acontecimientos abre un nuevo panorama en la historia contemporánea salvadoreña. Por un lado, nos permite analizar la estrategia de apertura restrictiva que el gobierno de Julio Rivera implementó. Asimismo, los condicionantes locales e internacionales que la acompañaron. Sin duda alguna, el examen de la década de los sesenta en El Salvador nos brinda una excelente pauta para comprender la conflictividad del decenio siguiente. Asimismo, permite reconstruir el surgimiento y accionar de muchos actores políticos - verbigracia el Partido Demócrata Cristiano (PDC)- que se convirtieron en protagonistas durante la guerra civil de nuestro país.

\section{Notas}

1 White, Alastair, El Salvador, UCA Editores, 2001, p. 133.

2 El 2 de septiembre de 1961, nace el Partido de Conciliación Nacional (PCN), que se fundó una vez consolidado el Directorio y vino a constituirse en el partido que gozó con el respaldo del grupo castrense que asestó el golpe de 1961. Lo que buscaba, según Mario Ayala, era disfrazar el mismo esquema oficialista para obtener mayor aceptación. Asimismo, el ideal básico subyacente en el PCN era el de ser el único partido nacional que podía conciliar los varios intereses de la sociedad

salvadoreña". Ayala, Mario et al, "Los procesos electorales en El Salvador de 1960 a 1989", tesis de licenciatura en Ciencias Jurídicas, El Salvador, Universidad Centroamericana "José Simeón Cañas”, 1990.

3 Gordon, Sara, Crisis politica y guerra en El Salvador, México, Siglo XXI, 1989, p. 86.

4 Rey, Dictadura, 2008, p. 131.

5 Hoja suelta "El PDC se retira del Consejo Consultivo Preelectoral". Véase, Prendes, Dictadura, 2008, p.31. 
6 Denominada también representación directa. Este sistema de representación adjudica todos los escaños parlamentarios disponibles en una jurisdicción territorial al partido que obtiene la mayoría de votos. En la mayoría de los casos, este sistema permite la composición unipartidista de un parlamento.

7 Biblioteca Virtual Miguel de Cervantes, Constitución Política de El Salvador 1962. [en línea] <http://bib.cervantesvirtual.com/servlet/SiveObras/> [consulta: 2 de mayo de 2011]

8 Julio Rivera, como un miembro más del Directorio Cívico Militar, no había ejercido la presidencia de la República $y$, por ende, se encontraba capacitado legalmente para competir en las próximas elecciones. La promesa formulada por este grupo de militares en enero de 1961,

9 Político salvadoreño. Fungió como vicepresidente de la República desde 1962 hasta 1967 bajo el primer gobierno del PCN. La selección de Lima, afirma Mario Ayala, fue significativa. Además de ser economista, con fuertes nexos con la Alianza para el Progreso, también era un abogado que representaba a algunas de las familias más acaudaladas del país y estaba emparentado por el matrimonio con la oligarquía. Creían que si alguien podía allanar el antagonismo natural entre la elite económica y el régimen reformista, ese era Lima". Asimismo, veintisiete años después, compitió por el mismo cargo bajo la coalición de izquierda Convergencia-FMLN. En estas elecciones presidenciales, realizadas en 1994 y las primeras tras los Acuerdos de Paz de Chapultepec, Alianza Republicana Nacionalista (ARENA) resultó vencedora, obteniendo la presidencia el Dr. Armando Calderón Sol.
10 Abogado de la República que participó en la fundación del PCN y fue designado Secretario de Relaciones Públicas de la Directiva Provisional de dicho partido en 1961. En su vida política se desempeñó como Presidente de la Asamblea Legislativa (1963) y la Corte Suprema de Justicia (1984-1989). Fue asesinado durante la guerra civil salvadoreña el 28 de noviembre de 1989.

11 Valle, Siembra, 1993, p. 59.

12 Dirección General de Publicaciones, "Mensaje del Coronel Julio Adalberto Rivera al pueblo salvadoreño al tomar posesión de la Presidencia de la República", en AGN de El Salvador. p. 31.

13 Ibid., p.31. Subrayado en el original.

14 El sistema de representación proporcional o escrutinio proporcional plurinominal es un sistema electoral en el que el porcentaje de votos que reciben los partidos políticos determina el número de escaños que les son asignados en las asambleas legislativas o parlamento. Este sistema de representación se distingue del sistema de representación directa porque casi todos los partidos políticos son representados en el cuerpo legislativo, sin importar que no obtengan mayoría relativa en ningún distrito electoral. Por lo tanto, también se llama sistema de representación plena.

15 Dirección General de Publicaciones, "Consejo Central de Elecciones elabora anteproyecto de reforma a la Ley Electoral", en AGN de El Salvador, pp. 32-33.

16 Nació en el Divisadero, departamento de Morazán, el 7 de julio de 1917. En su carrera militar obtuvo el título de General el 7 de mayo de 1969. Estudió en la Escuela de Armas Blindadas de Fort Knox, Estados Unidos, y en la 
Escuela de Estado Mayor en Madrid. Fue Agregado Militar de la embajada de El Salvador en Paris y Washington. De este último lugar fue llamado a colaborar en el Gabinete del presidente Julio Adalberto Rivera, bajo el cargo de Ministro del Interior, mismo que desempeñó desde el 1 de julio de 1962 hasta el 30 de junio de 1966. El 26 de octubre fue electo por el PCN como candidato a la presidencia de la República, puesto que ganó en las elecciones del 5 de marzo de 1967. Fungió como presidente hasta 1972 y en julio de 1969 comandó la guerra de las "Cien Horas" contra Honduras. Véase, Ministerio del Interior, "Fidel Sánchez Hernández, biografía", en AGN de El Salvador, Carpetas Leistenschneider, folder 11.

17 Dirección General de Publicaciones, "Decreto que reforma la Ley Electoral introduciendo la elección proporcional en la Asamblea Legislativa" en AGN de El Salvador, p. 36.

18 Ibid., pp. 36-37.

19 El grupo que elaboró el documentopropuesta para el gobierno estadunidense estuvo conformado por los siguientes funcionarios: Adolf Berle, Gordon Lincoln, Morales Carrión, Norman Thomas y Arthur Whitaker. Además, contaron con la asesoría de importantes políticos y economistas latinoamericanas, entre ellos: Raúl Prebisch, José Antonio Mayobre, Felipe Pazos -exiliado cubano- Rómulo Betancourt y José Figueres. Véase Levinson; Onís; Alianza, 1962, p. 65.

20 Alianza para el Progreso, documentos básicos, "Discurso del presidente Kennedy sobre América Latina", 1962, p. 3.

21 Levinson; Onís, Alianza, 1972, p. 46.

22 Dreier, Alianza, 1962, p. 103.
23 Katz, "Guerra", 2004, p.23.

24 Alianza para el Progreso, "Documentos oficiales emanados de la Reunión extraordinaria del Consejo Interamericano Económico y Social al Nivel Ministerial", Punta del Este, Uruguay 5-17 de agosto de 1961. p. 1.

25 Alianza para el Progreso: documentos básicos, "Discurso del presidente Kennedy sobre América Latina”, 1962, p. 7.

26 Ortega, Carta, 1966, p. 53.

27 Alianza para el Progreso: documentos básicos, "Discurso de Raúl Sáez, miembro del Comité de Nueve Expertos de la Alianza para el Progreso", 1962, p. 46.

28 Levinson; Onís, Alianza, 1972, pp. 74-75.

29 Alianza para el Progreso: documentos básicos, "Palabras pronunciadas por el presidente Kennedy ante los diplomáticos latinoamericanos reunidos en la Casa Blanca con motivo del primer aniversario de la enunciación de la Alianza para el Progreso", 1962, p. 41.

$30 \quad$ Ibid., p. 41.

31 Ibid., p. 38.

32 Lamentablemente no pudimos obtener los anteriores informes sobre las Jornadas de la ALPRO. No obstante, la diversidad de sectores políticos, empresariales y académicos presentes en esta cuarta Jornada nos permite reconstruir -tomando esta reunión como muestrala discusión que suscitó la implementación de las reformas estipuladas por la ALPRO en el país.

33 En abril de 1962 se creó en El Salvador el Consejo de Planificación y Coordinación Económica. Además, se establecieron grupos de trabajo en algunas secretarías de Estado que tuvieron a su 
cargo preparar y dirigir varios programas sectoriales. Véase, Aranda, Punta del Este, 1966, p. 68.

34 Oficina de la Unión Panamericana de El Salvador, "El Sector Privado y la Alianza para el Progreso", en AGN de El Salvador, pp. 7-8.

35 Ibid., p. 11.

36 Ibid., p. 7.

37 Ibid., pp. 17-18.

38 Ibid., pp. 26-27.

39 Abogado de la República. En su vida política se desempeñó como miembro del Directorio Cívico Militar, mismo al que renunció el 7 de abril de 1961. Miembro honorario de la Fundación Salvadoreña para el Desarrollo Económico y Social (FUSADES), fungía como Ministro de la Presidencia del gobierno de Alfredo Cristiani (ARENA) cuando fue asesinado el 9 de junio de 1989

40 Oficina de la Unión Panamericana de El Salvador, "El Sector Privado y la Alianza para el Progreso", en AGN de El Salvador, pp. 15-16.

41 Ibid., p. 16.

42 Abogado y economista salvadoreño. Se desempeñó como Ministro de Economía en el gobierno de José María Lemus. Además, fue funcionario de la Organización de Estados Americano (OEA).

43 Oficina de la Unión Panamericana de El Salvador, "El Sector Privado y la Alianza para el Progreso", en AGN de El Salvador, p. 21.

44 Aunque el año de 1965 está fuera de nuestro marco temporal, resulta clave señalar que este informe contenía las actividades que el gobierno realizó desde el primero de julio de 1964. Por consiguiente, resulta fundamental en nuestra investigación.

45 Secretaría de Comunicación de la Presidencia, "Coronel Julio Rivera, Informe Presidencial del Tercer año de Gobierno". en AGN El Salvador. p. 57.

46 Bataillon, Génesis, 2008, p. 87.

47 "Reunión anticomunista Inaugurada en la ODECA", La Prensa Gráfica, 14 de enero de 1964.

48 "Ministros de Centroamérica acuerdan fortalecer la defensa", La Prensa Gráfica, 18 de enero de 1964

49 Kennedy, Respuesta, 1968, p. 14.

50 Ibid., p. 149.

51 Dirección General de Publicaciones, "Discurso pronunciado por el señor presidente de la República, Coronel Julio Adalberto Rivera, con motivo de celebrarse la sesión inaugural de la honorable Asamblea Legislativa", en AGN de El Salvador, p. 245.

52 CEPAL, Notas, 1980

53 Ibid.

54 CEPAL, XII- 1989:24. (Estimaciones en dólares estadunidenses de 1980)

55 CEPAL, Anuario... 1990: 734-743.

56 Ellacuría, "El desafío", 1990, pp. 10751080.

57 Dirección General de Publicaciones, "Discurso pronunciado por el señor presidente de la República, Coronel Julio Adalberto Rivera, con motivo de celebrarse la sesión inaugural de la honorable Asamblea Legislativa", en AGN de El Salvador. p. 241.

58 Secretaría de Comunicación de la Presidencia, "Coronel Julio Rivera, Informe Presidencial del Tercer año de Gobierno", en AGN de El Salvador. p. 57. 
59 Bataillon, Génesis, 2008, pp. 87-88.

60 Departamento de Relaciones Públicas de Casa Presidencial, "Palabras del señor presidente de la República, coronel Julio Adalberto Rivera, en la inauguración de la segunda Reunión de Ministros de Gobernación de Centroamérica y Panamá", efectuada en la sede de la ODECA, el 13 de enero de 1964. en AGN México, Comunicaciones de los embajadores mexicanos en El Salvador. Caja 4, f 230.

61 Editorial, "Un compromiso histórico: las próximas elecciones", La Prensa Gráfica, 22 de octubre de 1963.

62 Ibid.

63 Abogado y político salvadoreño, originario del departamento de San Miguel, fue uno de los fundadores del partido Demócrata Cristiano en noviembre de 1961. En este instituto político desempeñó diversas funciones, distinguiéndose su candidatura presidencial en las elecciones de 1967, donde resultó electo el coronel Fidel Sánchez Hernández.

64 Dirección General de Publicaciones, "El presidente Rivera confirmó a los partidos que está garantizada la libertad de elecciones", en AGN de El Salvador, p.180.

65 Ibid., p. 180.

66 Ibid., p. 180.

67 "El PAR y las elecciones", Tribuna Libre, 15 de septiembre de 1963.

68 Dirección General de Publicaciones, "Decreto transitorio", en AGN de El Salvador, p.119.

69 Abogado e historiador. Fundador del PDC y uno de sus dirigentes en la década de los sesenta. Además, fungió como diputado en la Asamblea Legislativa.
70 Dirección General de Publicaciones, "PDC dirige exposición al presidente Rivera", en AGN de El Salvador, p. 78.

71 "Reiteran garantías a elecciones libres", Tribuna Libre, 11 de septiembre de 1963.

72 "Rivera reúnase con Gobernadores Departamentales", El Diario de Hoy, 11 de octubre de 1963.

73 Ibid.

74 Roberto Hernández, "Tiempo para formar la coalición política” La Prensa Gráfica, 10 de noviembre de 1963.

75 La Directiva Nacional del Partido Revolucionario Abril y Mayo, "El PRAM no los olvida nunca" Comunicado al pueblo salvadoreño, San Salvador 8 de diciembre de 1964, en Centro de Información y Apoyo a la Investigación (CIDAI), UCA, San Salvador.

76 La Directiva Nacional del Partido Revolucionario Abril y Mayo, "El PRAM llama a votar contra el partido oficial" San Salvador 10 de febrero de 1964, en Centro de Información y Apoyo a la Investigación (CIDAI), UCA, San Salvador.

77 Ibid.

78 Ibid.

79 Ibid. Mayúsculas en el original.

80 El artículo reza de la siguiente forma según la Constitución Política de 1962: "La Fuerza Armada es apolítica y esencialmente obediente, y no puede deliberar en asuntos de servicio. Su organización y el desarrollo de sus actividades estarán sujetos a Leyes, Reglamentos y Disposiciones Especiales".

81 "Disposición de defensa ratifica apoliticidad", La Prensa Gráfica, 19 de febrero de 1964. 
82 "Resultados generales de las elecciones, datos del CCE", El Diario de Hoy, 14 de marzo de 1964.

83 Rey, Dictadura, 2008, p. 161.

84 Alianza para el Progreso, "Documentos oficiales emanados de la Reunión extraordinaria del Consejo Interamericano Económico y Social al Nivel Ministerial", Punta del Este, Uruguay 5-17 de agosto de 1961. p. 1.

85 Don Quijote, "Molino de viento", El Diario de Hoy, 12 de marzo de 1964.
86 "Resultados generales de las elecciones, datos del CCE", El Diario de Hoy, 14 de marzo de 1964.

87 José Rubén Saavedra, "El eco de las elecciones", Diario Latino, 12 de marzo de 1964.

88 Rafael Mora Maza, "Un ensayo bastante bueno", La Prensa Gráfica, 12 de marzo de 1964.

89 Tarquino Humberto Rosales, "Hemos pasado el Rubicón” La Prensa Gráfica, 14 de marzo de 1964. 